\title{
A Comparison of Costs of Medicare Part D Prescriptions Dispensed at Retail and Mail Order Pharmacies
}

\author{
Norman V. Carroll, PhD
}

\section{ABSTRACT}

BACKGROUND: Plan sponsors encourage the use of mail order pharmacies because they believe mail order dispensing will lower their prescription drug costs. Health plans and pharmacy benefit management companies (PBMs) usually offer patients substantially lower copayments to incentivize them to use mail order pharmacies. A number of health plans and PBMs now require patients to use these pharmacies for maintenance prescriptions.

OBJECTIVES: To (a) compare costs for prescriptions dispensed through mail order and retail pharmacies in Medicare Part D plans and (b) examine whether mail order or retail pharmacies provided lower all third-party costs for each of the top 300 products; the relationship between whether a product was available generically and whether mail order or retail pharmacies provided lower prices; and the generic substitution rates at mail order and retail pharmacies.

METHODS: The sample for this study consisted of 2010 Medicare Part D prescription drug data for the 300 products with the highest sales at mail order pharmacies. The prescriptions included in the study were dispensed in the initial coverage limit phase of Part $D$ by retail or mail order pharmacies to patients who were insured by Part $D$ for 12 months in 2010, who received no Part D subsidies, and who were alive for the full year in 2010. Mean-per-unit costs were calculated for both mail order and retail prescriptions for each of the top 300 products. Products were defined by Medi-Span Generic Product Indentifier. Summary statistics for the overall costs of mail order and retail prescriptions were calculated as the weighted mean-per-unit costs of the top 300 products. The weighting factor for both mail order and retail prescriptions included both the mail order quantity dispensed per prescription and the number of prescriptions dispensed. Weighting both mail and retail prescriptions by mail order quantities dispensed and numbers of prescriptions ensured that the results reflected actual cost differences rather than differences in the mix or quantities of prescriptions dispensed. These calculations were made for total costs, costs covered by the Medicare Standard Benefit (MSB), costs paid by all third-party payers (including Medicare), and patient costs.

RESULTS: The top 300 products accounted for $84.8 \%$ of mail order costs. Among all prescriptions in the sample-both mail order and retail-mail order prescriptions accounted for $7.8 \%$ of prescriptions dispensed and $14.1 \%$ of total spending. Comparison of 90 -day or greater supplies indicated that costs per unit of medication for retail pharmacies were lower for total costs (\$0.94 for retail pharmacies vs. $\$ 0.96$ for mail order pharmacies), MSB costs (\$0.59 for retail pharmacies vs. $\$ 0.63$ for mail order pharmacies), and all third-party payer costs (\$0.64 for retail pharmacies vs. $\$ 0.72$ for mail order pharmacies), but higher for patient costs ( $\$ 0.31$ for retail pharmacies vs. \$0.24 for mail order pharmacies). Retail pharmacies had lower all third-party payer costs for 244 products, while mail pharmacies had lower costs for 56 products. Retail pharmacies were more likely to have lower costs for products that included generic alternatives, while mail order pharmacies were more likely to have lower costs for products that included only branded drugs. Generic substitution rates were $91.4 \%$ for retail pharmacies versus $\mathbf{8 8 . 8 \%}$ for mail order pharmacies. Results from secondary analyses that compared all prescriptions which met the inclusion criteria, regardless of days supply, and that compared exactly 90-day supplies, yielded similar results.

CONCLUSIONS: Third-party payers, including Medicare, paid more for prescriptions dispensed at mail order pharmacies than for those dispensed at retail pharmacies in the Medicare Part D program. The higher payments appeared to result, for the most part, because of higher patient cost sharing at retail pharmacies. Further, total costs-including both third-party payer and patient payments-for 90-day and 90-day or greater supplies were lower at retail pharmacies than at mail pharmacies. These results suggest that, all other things being equal, Medicare Part $D$ plan sponsors do not realize savings when patients use mail order pharmacies.

J Manag Care Pharm. 2014;20(9):959-67

Copyright $\odot 2014$, Academy of Managed Care Pharmacy. All rights reserved.

\section{What is already known about this subject}

Plan sponsors use mail order pharmacies to attempt to control drug spending.

Plan sponsors offer patients lower copayments to incentivize them to use mail order pharmacies.

Studies in commercial patient populations have provided mixed results about whether plan sponsors realize savings from mail order pharmacies.

\section{What this study adds}

When comparing 90-day or greater mail order supplies with 90-day or greater retail supplies, retail pharmacies provide lower total prescription costs, lower Medicare Standard Benefit (MSB) costs, lower third-party payer costs, but higher patient costs. When comparing mail order and retail prescriptions, regardless of days supply, retail pharmacies provide lower third-party payer costs, similar MSB costs, but higher total and patient costs.

Retail pharmacies provide slightly higher rates of generic substitution than mail order pharmacies.

Retail pharmacies provide lower prices for generic products, while mail order pharmacies provide lower prices for branded products. 
$\mathrm{M}$ ost health plans and pharmacy benefit management companies (PBMs) offer patients a choice of mail order or retail pharmacy service for their prescriptions. Although patients are usually offered lower copayments if they use mail order, they can pay higher copayments and continue to use retail pharmacies. Over the past several years, and outside of Medicare Part D, a number of health plans and PBMs have implemented mandatory programs that require patients to use mail order pharmacies for maintenance prescriptions. ${ }^{1,2}$

Plan sponsors subsidize copayments for patients who use mail order pharmacies based on the belief that mail order dispensing will lower their spending on prescriptions. Mail order pharmacies claim to offer lower costs to plan sponsors as a result of more efficient dispensing operations and volume purchasing of generic drugs. ${ }^{3-6}$ However, the fact that mail order pharmacies may have the ability to provide lower unit costs for prescriptions does not necessarily mean that plan sponsors realize lower costs by using mail order pharmacies. The use of different ingredient cost schedules for mail and retail pharmacies, differences in utilization and wastage rates, and differences in rates of generic substitution could lower the savings that health plans actually realize through mail order pharmacies. Further, discounting copayments directly and substantially reduces any savings that plan sponsors may realize.

The few available studies suggest that when samples of the same products are compared mail order dispensing is associated with lower total costs and lower costs to patients but not necessarily lower costs to plan sponsors. ${ }^{7-10}$ The copayment reductions that are used to induce patients to use mail order pharmacies shift costs from patients to plan sponsors. The greater the extent to which retail copayments are higher than mail order copayments, the smaller the mail order savings realized by plan sponsors. Further, copayment reductions may have a substantial effect on use of mail order pharmacies. The greater the copayment reductions, the more likely patients are to use mail order pharmacies. ${ }^{10}$ Thus, plan sponsors may reduce copayments to incentivize patients to use mail order, but lower copayments reduce savings that plan sponsors realize from mail order dispensing.

Savings may also be affected by differences in rates of generic drug use between mail and retail pharmacies. Results of past research are mixed on this issue. In a study based on data from 5 large PBMs, Wosinska and Huckman (2004) found generic substitution rates (the number of prescriptions dispensed as generics divided by the number of prescriptions for which generic alternates were available) were $92.99 \%$ for mail pharmacies and $92.02 \%$ for retail pharmacies. ${ }^{11}$ Johnsrud et al. (2007) found that generic dispensing rates (the number of prescriptions dispensed as generics divided by the total number of prescriptions dispensed) were $4 \%-5 \%$ higher in retail pharmacies than in mail pharmacies for a matched market basket of the products most commonly dispensed by mail order pharmacies. ${ }^{7}$

There are gaps in the current literature. First, none of the existing studies have specifically examined mail order use or costs in the Medicare Part D population. The Medicare population is older and sicker than the commercially insured population, so they probably use more prescription drugs and a different mix of drugs. Second, plans have only recently begun to reimburse retail pharmacies for 90-day supplies of chronic medications. Various sources suggest that plans rarely reimbursed for 90-day retail supplies prior to 2006.12,13 In 2006, the use of 90-day retail pharmacies increased substantially as a result of the implementation of Medicare Part D and its requirement that plans that offered 90-day supplies at mail order pharmacies must also offer 90-day supplies at retail pharmacies..$^{14,15}$ The use of 90-day retail pharmacies was further enhanced in 2008, when Walmart expanded its discount generic program to cover 90-day supplies of selected medications for $\$ 10$, and in January 2009, when CVS/Caremark introduced its Maintenance Choice plan. ${ }^{15,16}$ Because 90-day supplies at retail pharmacies have only recently become common, few cost comparisons of 90-day retail and mail order pharmacy costs have been published. Finally, there has been little research into differences in generic substitution rates between mail order and retail pharmacies, and the existing research provides conflicting results. Given the impact that generic substitution has on costs, this impact is an important area for research.

The objective of this study was to compare total costs, costs covered by the Medicare Standard Benefit (MSB), all third-party payer costs, and costs paid by patients for prescriptions dispensed through mail order and retail pharmacies to patients in Medicare Part D plans. A secondary objective was to examine whether mail order or retail pharmacies provided lower all third-party costs for each of the top 300 products; the relationship between whether a product was available generically and whether mail order or retail pharmacies provided lower prices; and the generic substitution rates at mail order and retail pharmacies.

\section{Methods}

\section{Data Sources}

The sample of prescriptions for this study was selected from 2010 prescription drug event (PDE) data supplied by the Centers for Medicare and Medicaid Services (CMS). PDEs are records of dispensed prescriptions and are roughly comparable to prescription claims. ${ }^{17}$ Figure 1 shows exclusion and inclusion criteria used to generate the final sample.

The following CMS data files for the 2010 year were used for this study:

- The Master Beneficiary Summary file included de-identified data describing Part D patients and the prescription drug plans in which they were enrolled. This file included a 5\% random sample of Medicare Part D patients, which provided a total of 2,727,742 patients. 


\section{FIGURE 1 Sample Selection Flowchart}
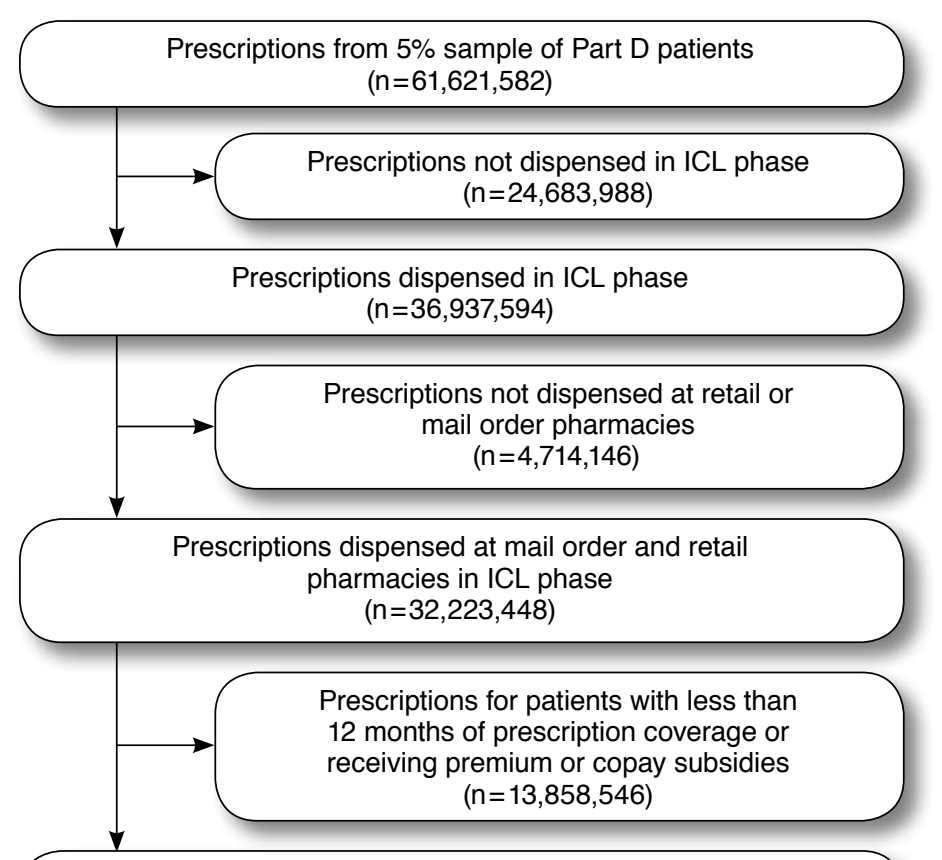

Prescriptions dispensed at mail order and retail pharmacies in ICL phase to patients with 12 months of coverage and not receiving subsidies $(n=18,364,902)$

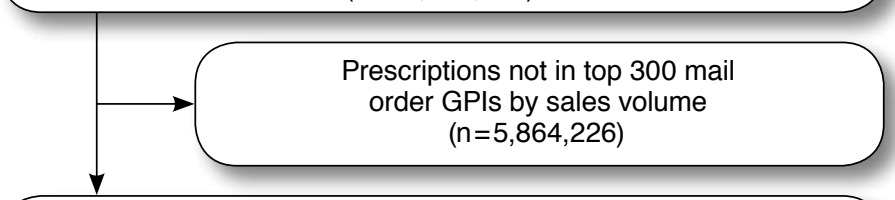

Prescriptions for top $300 \mathrm{GPIs}$ dispensed at mail order and retail pharmacies in ICL phase to patients with 12 months of coverage and not receiving subsidies $(n=12,500,676)$

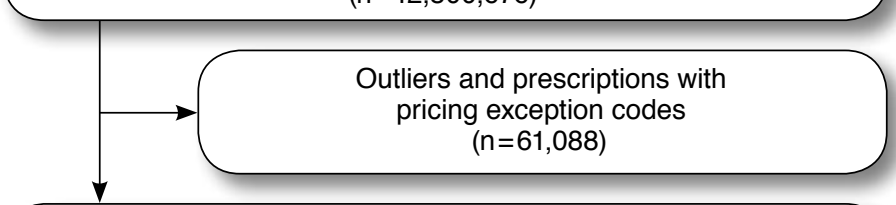

Prescriptions for top $300 \mathrm{GPIs}$ dispensed at mail order and retail pharmacies in ICL phase to patients with 12 months of coverage and not receiving subsidies, after removing outliers and prescriptions with pricing exception codes $(n=12,439,588)$

Prescriptions with less than 90-day supplies $(n=9,728,571)$

Prescriptions for 90-day or greater supplies of top 300 GPIs dispensed at mail order and retail pharmacies in ICL phase to patients with 12 months of coverage and not receiving subsidies, after removing outliers and prescriptions with pricing exception codes $(\mathrm{n}=2,711,017)$

GPI = Generic Product Indentifier; ICL = initial coverage limit.
- The Prescription Drug Events and Drug Characteristics files provided information about prescriptions dispensed to Part D patients. These files included such information as drug name, strength, and dosage form; quantity dispensed; date dispensed; and payment sources. The files included information on 61,621,582 PDEs.

- The Pharmacy Characteristics file included information on 66,685 participating pharmacies. Information included pharmacy type (e.g., mail or retail), the state in which the pharmacy was located, and whether it was part of a chain.

All files included identification numbers that allowed the researcher to link patients and organizations within the datasets, but not to identify specific individuals or organizations Files with patient data were linked using the "BENE_ID" variable. Files with pharmacy data were linked using the "CCW_ PHARMACY_ID" variable.

\section{Inclusion and Exclusion Criteria}

The original files provided by CMS included data on all types of Medicare patients and pharmacies and on prescriptions dispensed to these patients and from these pharmacies. The following exclusions were made to develop the final data sample.

First, only PDEs that were dispensed in the initial coverage limit phase of Part D coverage were included in the sample for this study. This restriction on inclusion was necessary because the relative levels of patient and plan costs differ greatly across benefit phases. On average, patients pay $100 \%$ of the drug cost in the deductible phase, approximately $25 \%$ in the initial coverage limit phase, $100 \%$ in the coverage gap, and $5 \%$ in the catastrophic coverage phase. The relative levels of patient and plan costs are more consistent within the initial coverage limit phase, the phase in which most prescriptions are dispensed.

Second, only PDEs that were dispensed in retail or mail order pharmacies were included. The original sample also included prescriptions dispensed by other types of pharmacies (e.g., long-term care pharmacies, specialty pharmacies, and nuclear pharmacies).

Third, the sample included only patients who were insured by Part D for 12 months in 2010. Patients who received either Medicaid, retiree drug subsidies, or other premium or copayment subsidies at any time during 2010 and patients who died during 2010 were excluded from the sample.

Fourth, a small number of PDEs that appeared to be outliers were excluded. For example, there were a number of PDEs for which the quantity dispensed was unusually high (e.g., 25,000 tablets dispensed) and a number for which total costs were unusually low (e.g., less than \$1). PDEs were excluded if the total prescription cost was less than $\$ 1$, if the total quantity dispensed was greater than 1,000 , or if the total prescription cost per unit was $\$ 500$ or greater. PDEs with a pricing exception code were also excluded. These were prescriptions that 


\begin{tabular}{|c|c|}
\hline Component & Definition \\
\hline Total cost & $\begin{array}{l}\text { The total cost of a Medicare Part D prescription is defined as the sum of covered D plan paid amount, noncovered plan paid amount, } \\
\text { low-income cost share, other TrOOP amount, patient liability reduction due to other payer amount, and patient payment. }\end{array}$ \\
\hline $\begin{array}{l}\text { Covered D plan } \\
\text { paid amount }\end{array}$ & The amount paid by Medicare as part of the standard Medicare Part D benefit. \\
\hline $\begin{array}{l}\text { Noncovered plan } \\
\text { paid amount }\end{array}$ & $\begin{array}{l}\text { The amount paid by the Part D plan that exceeds the Medicare Part D standard benefit. Noncovered plan paid amounts arise when } \\
\text { plans offer enhanced benefit plans to patients. The enhanced benefits include payment for drugs that are not covered by Part D and/ } \\
\text { or reduced patient cost sharing. }\end{array}$ \\
\hline $\begin{array}{l}\text { Low-income } \\
\text { cost share }\end{array}$ & The amount paid by Medicare to reduce the cost share for low-income patients. \\
\hline $\begin{array}{l}\text { Other TrOOP } \\
\text { amount }\end{array}$ & $\begin{array}{l}\text { "All qualified third-party payments that contribute to a beneficiary's TrOOP" except for low-income subsidies and patient payments. } \\
\text { Other TrOOP amounts are payments made on the patient's behalf by, for example, state pharmacy assistance programs or charities. } \\
\text { TrOOP costs are the payments that count toward determining when a patient enters the catastrophic phase of Part D coverage. }\end{array}$ \\
\hline $\begin{array}{l}\text { Patient liability } \\
\text { reduction due to } \\
\text { other payer amount }\end{array}$ & $\begin{array}{l}\text { "Amounts by which patient liability is reduced due to payment by other payers that are not TrOOP-eligible and do not participate in } \\
\text { Part D. Examples of non-TrOOP-eligible payers: group health plans, worker's compensation, and governmental programs (e.g., VA, } \\
\text { TRICARE)."30 }\end{array}$ \\
\hline Patient paid amount & The amount paid by the patient. \\
\hline $\begin{array}{l}\text { All third-party } \\
\text { payer costs }\end{array}$ & $\begin{array}{l}\text { In this study "all third-party payer costs" was defined as all prescription drug costs not paid by the patient. This was defined as the } \\
\text { sum of covered D plan paid amount, noncovered plan paid amount, other TrOOP amount, and patient liability reduction. This study } \\
\text { did not include patients receiving LICS. }\end{array}$ \\
\hline $\begin{array}{l}\text { Medicare standard } \\
\text { benefit costs }\end{array}$ & $\begin{array}{l}\text { In this study, "Medicare standard benefit costs" was defined as the costs paid by the Medicare program as part of the standard benefit. } \\
\text { This is the same as Medicare covered D plan paid amount. }\end{array}$ \\
\hline
\end{tabular}

were dispensed out of network, with Medicare as the secondary payer, or with other special pricing instructions. PDEs with pricing exception codes were excluded because they had atypical prices. For example, a prescription dispensed out of network would have had a higher price to the patient and a lower price to third-party payers than the same prescription dispensed in network. A total of $0.49 \%$ of PDEs were excluded based on the pricing exception code or for being outliers.

Finally, the sample included only those PDEs for drugs in the top 300 products dispensed by mail order pharmacies in 2010. Products were defined by the Medi-Span Generic Product Identifier (GPI; Wolters Kluwer Health, Indianapolis, IN). Each GPI includes all products with the same active ingredients, strength, route of administration, and dosage form. Branded drugs and their generic equivalents are classified into the same GPI. Identification of the top 300 products was based on total costs. Limiting the sample to these products allowed for mail order and retail pharmacy costs to be compared for the same sample of products. This limitation was important because mail order and retail pharmacies dispense different mixes of products. Mail order pharmacies dispense primarily maintenance drugs, while retail pharmacies dispense both maintenance drugs and those used for acute needs. While the specific GPIs to be included in the sample were identified using the mail order sample, the sample that was used for the analysis included prescriptions for these 300 GPIs that were dispensed in both retail pharmacies and mail order pharmacies.

\section{Analysis}

The primary analysis for this study compared costs for 90-day or greater supplies dispensed at mail order pharmacies with the costs of 90-day or greater supplies dispensed at retail pharmacies. Secondary analyses compared all prescriptions that met the inclusion criteria, regardless of days supply dispensed and prescriptions for exactly 90-day supplies.

Mean-per-unit costs were calculated for total costs, all thirdparty payer costs, MSB costs, and patient costs. These 4 costs were calculated for each product (as defined by GPI) for mail order prescriptions and for retail prescriptions. Total costs were defined as all amounts paid for a prescription, regardless of who paid them. All third-party payer costs were defined as all amounts not paid by the patient. MSB costs were defined as amounts paid by Medicare as part of the standard Medicare Part D benefit. Table 1 provides a more complete explanation of the various components of the costs of a Part D prescription provided in Medicare Part D data.

Mean-per-unit costs for all third-party payers were compared to determine the number of products for which mail order pharmacies had lower costs and the number for which retail pharmacies had lower costs. A chi-square test was used to determine the association between the channel (mail order or retail) having the lower cost and whether the product included only branded products or both branded and generic products.

Next, an analysis was conducted to provide a summary statistic that compared costs between mail order and retail pharmacies over all 300 products (Table 2). The mean-perunit cost for mail order pharmacies (across all 300 products) 
TABLE 2 Medicare Part D Retail and Mail Order Total Costs Per Unit for Top 300 Products

\begin{tabular}{|c|c|c|c|c|}
\hline Product (Defined by GPI)a & $\begin{array}{c}\text { Mail Order Total Cost } \\
\text { Per Unit }(\$)^{\mathrm{b}}\end{array}$ & $\begin{array}{l}\text { Retail Total Cost } \\
\text { Per Unit }(\$)^{\mathrm{c}}\end{array}$ & $\begin{array}{c}\text { Mail Order } \\
\text { Prescriptions } \\
\text { Dispensed }(\mathrm{N})^{\mathrm{b}}\end{array}$ & $\begin{array}{l}\text { Mean Mail Order } \\
\text { Quantity Dispensed } \\
\text { Per Prescription }\end{array}$ \\
\hline Valocyclovir tab $500 \mathrm{mg}$ & 5.0183 & 4.7710 & 117 & 100.368 \\
\hline Hydroxychloroquine tab $200 \mathrm{mg}$ & 0.3284 & 0.2900 & 1,994 & 159.671 \\
\hline Methotrexate tab $2.5 \mathrm{mg}$ & 0.6837 & 0.5510 & 1,207 & 74.341 \\
\hline Anastrozole tab $1 \mathrm{mg}$ & 8.6693 & 7.9780 & 1,102 & 90.172 \\
\hline Exemestane tab $25 \mathrm{mg}$ & 10.8892 & 11.1810 & 101 & 90.693 \\
\hline Letrozole tab $2.5 \mathrm{mg}$ & 12.9797 & 13.2550 & 334 & 89.985 \\
\hline Testosterone gel 1\% $50 \mathrm{mg}$ & 1.6249 & 1.6560 & 121 & 470.455 \\
\hline Testosterone gel pump 1\% & 1.6082 & 1.6120 & 98 & 490.561 \\
\hline Conjugated estrogen tab $0.3 \mathrm{mg}$ & 1.6074 & 1.6370 & 1,269 & 87.574 \\
\hline Brimonidine tartrate ophthalmic solution $0.15 \%$ & 11.1388 & 10.6658 & 315 & 23.889 \\
\hline Cylosporine ophthalmic emulsion $0.05 \%$ & 3.6655 & 3.7494 & 552 & 176.196 \\
\hline Brinzolamide ophthalmic suspension $1 \%$ & 8.7483 & 8.9654 & 414 & 26.353 \\
\hline Lidocaine $5 \%$ patch & 6.2273 & 6.3283 & 105 & 105.429 \\
\hline Weighted mean & $0.9618^{\mathrm{d}}$ & $0.9446^{\mathrm{e}}$ & & \\
\hline \multicolumn{5}{|c|}{ 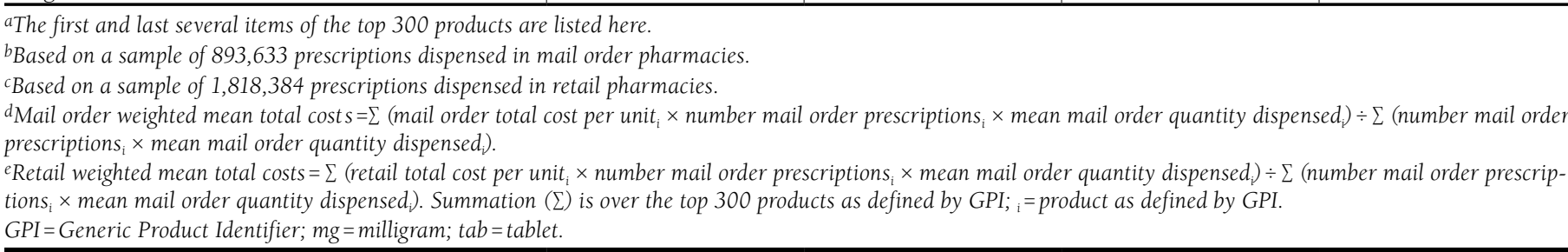 } \\
\hline
\end{tabular}

was calculated by weighting each product's mean mail order per-unit cost by both mean mail order quantity dispensed and number of mail order prescriptions dispensed. The mean-perunit cost for retail pharmacies (across all 300 products) was calculated by weighting each product's mean retail per-unit cost by both mean mail order quantity dispensed and number of mail order prescriptions dispensed. Weighting retail costs for each product with mail order quantities and numbers of prescriptions dispensed for that product ensured that any differences noted between overall mail order and retail costs would be due to actual cost differences and not to differences in quantities dispensed or numbers of prescriptions dispensed within products. These calculations were made for total costs, all third-party payer costs, MSB costs, and patient costs.

Generic substitution rates were calculated for the top 300 products. The product dispensed for each PDE was classified using the Medi-Span Source Code (Wolters Kluwer Health, Indianapolis, IN), as either a colicensed brand, single-source brand, brand with generic alternative, or generic. The generic substitution rate was calculated as the number of generic prescriptions dispensed, divided by the total number of prescriptions dispensed for which generic alternatives were available. For this calculation, the numerator was all prescriptions classified as "generic," and the denominator was all prescriptions classified as "generic" or "brands with generic alternatives."

The data also included dispense as written (DAW) codes for situations in which generic alternatives were available for prescribed products but in which branded products were dispensed (Table 3). Three of the codes described situations in which the pharmacist had no choice but to dispense a branded product. These were "Substitution Not Allowed by Physician," "Substitution Not Allowed-Brand Drug Mandated by Law," and "Substitution Allowed-Generic Drug Not Available in Marketplace." Because the pharmacist was required to dispense a brand product in these situations, we reduced the denominator of the generic substitution ratio by the number of prescriptions dispensed with these codes.

If the proportions of prescriptions dispensed in each GPI were different between mail order and retail pharmacies, then comparing unweighted generic substitution rates could be misleading. To adjust for this discrepancy, the analysis calculated the mean generic substitution rate for each GPI for both mail and retail pharmacies, then calculated the weighted mean rate across all GPIs using the number of mail order prescriptions dispensed as the weighting factor. This calculation ensured that any differences found between mail order and retail pharmacies would be due to actual differences in generic substitution rates and not to differences in numbers of prescriptions dispensed within GPIs.

Virginia Commonwealth University's Institutional Review Board determined that the study qualified for exemption because it analyzed existing data that were de-identified. 


\begin{tabular}{|c|c|c|}
\hline \multirow[b]{2}{*}{$0=$ No product selection indicated } & Retail, n (\%) & Mail Order, n (\%) \\
\hline & $1,767,687 \quad(97.3)$ & $860,578 \quad(96.3)$ \\
\hline $\begin{array}{l}1=\text { Substitution not allowed } \\
\text { by prescriber }\end{array}$ & 26,688 & $14,207 \quad(1.6)$ \\
\hline $\begin{array}{l}2=\text { Substitution allowed: patient } \\
\text { requested brand product }\end{array}$ & $19,739 \quad(1.1)$ & 5,405 \\
\hline $\begin{array}{c}3=\text { Substitution allowed: pharmacist } \\
\text { selected product dispensed }\end{array}$ & $354(>0.1)$ & $18(>0.1)$ \\
\hline $\begin{array}{l}4=\text { Substitution allowed: generic } \\
\text { drug not in stock }\end{array}$ & $256(>0.1)$ & $26(>0.1)$ \\
\hline $\begin{array}{l}5=\text { Substitution allowed: brand drug } \\
\text { dispensed as generic }\end{array}$ & $597(>0.1)$ & 13,233 \\
\hline $6=$ Override & $115(>0.1)$ & $0 \quad(>0.1)$ \\
\hline $\begin{array}{l}7=\text { Substitution not allowed: } \\
\quad \text { brand drug mandated by law }\end{array}$ & $1,261 \quad(0.1)$ & $156(>0.1)$ \\
\hline $\begin{array}{c}8=\text { Substitution allowed: generic drug } \\
\text { not available in marketplace }{ }^{\mathrm{b}}\end{array}$ & $641 \quad(>0.1)$ & $10(>0.1)$ \\
\hline $9=$ Other & $46 \quad(>0.1)$ & $0 \quad(>0.1)$ \\
\hline Total & $1,817,384(100.0)$ & $893,633(100.0)$ \\
\hline \multicolumn{3}{|c|}{$\begin{array}{l}\text { a90-day or greater supplies. } \\
\text { bThe denominator of the generic substitution rate calculations was reduced by these } \\
\text { amounts because these represented situations where the pharmacist had no choice } \\
\text { but to dispense a branded product. }\end{array}$} \\
\hline
\end{tabular}

\section{Results}

The top 300 products dispensed from mail order pharmacies accounted for $84.8 \%$ of total mail order pharmacy costs. Among all prescriptions-both retail and mail order-for the top 300 products, mail order accounted for $7.8 \%$ of Part D prescriptions and $14.1 \%$ of total spending. A comparison of mail order versus retail costs for 90-day or greater supplies follows.

The sample for this comparison included 1,818,384 retail prescriptions and 893,633 mail order prescriptions dispensed to 429,827 patients. The mean days supply for 90 -day or greater prescriptions dispensed by retail pharmacies was 90.3. By comparison, the mean days supply for 90-day or greater prescriptions dispensed by mail order pharmacies was 90.7. Less than $0.1 \%$ of prescriptions were dispensed with colicensed brands; $8.5 \%$ were dispensed with single-source brands; $8.8 \%$ were dispensed with brands that had generic alternatives; and $82.7 \%$ were dispensed with generic products. Table 3 shows the number and percentage of prescriptions by DAW code for mail and retail pharmacies. The 300 products in the sample included 246 products that were oral, solid dosage forms. The remaining products included insulin vials and pens, topical patches, aerosol sprays, eye drops, and creams.

Retail pharmacies had lower all third-party payer costs for 244 products, while mail order pharmacies had lower costs for 56 products. Retail pharmacies were more likely to have lower costs for products that included generic alternatives, while mail order pharmacies were more likely to have lower costs for products that included only branded products. The differences were statistically significant (chi-square with $1 \mathrm{df}=33.4, P<0.001$ ).
Mean-per-unit costs of medication for retail pharmaciesover all 300 products-were lower for total costs ( $\$ 0.94$ for retail vs. $\$ 0.96$ for mail order), all third-party payer costs ( $\$ 0.64$ for retail vs. $\$ 0.72$ for mail order), MSB costs ( $\$ 0.59$ for retail vs. $\$ 0.63$ for mail order), and higher for patient costs (\$0.31 for retail vs. $\$ 0.24$ for mail order). All differences were statistically significant at $P<0.001$. The generic substitution rate for 90-day or greater supplies, after accounting for DAW codes, was $88.8 \%$ for mail order pharmacies, as compared with 91.4\% for retail pharmacies $(P<0.01)$.

\section{Secondary Analyses}

A secondary analysis compared mean-per-unit costs of medication for prescriptions dispensed for exactly 90-day supplies. Mean unit costs for retail pharmacies-over all 300 products-were lower for total costs $(\$ 0.99$ for retail vs. $\$ 1.01$ for mail order), lower for all third-party payer costs $(\$ 0.67$ for retail vs. $\$ 0.76$ for mail order), lower for MSB costs ( $\$ 0.62$ for retail vs. $\$ 0.67$ for mail order), and higher for patient costs ( $\$ 0.32$ for retail vs. $\$ 0.25$ for mail order). All differences were statistically significant at $P<0.001$.

An additional analysis compared mean-per-unit costs of medication for all prescriptions dispensed, regardless of days supply. For this analysis, the median days supply dispensed was 30 days for retail pharmacies and 90 days for mail order pharmacies. Mean unit costs for retail pharmacies_over all 300 products-were higher for total costs $(\$ 1.03$ for retail vs. $\$ 0.98$ for mail order), lower for all third-party payer costs ( $\$ 0.70$ for retail vs. $\$ 0.73$ for mail order), about the same for MSB costs ( $\$ 0.64$ for retail vs. $\$ 0.64$ for mail order), and higher for retail pharmacies for patient costs ( $\$ 0.33$ for retail vs. $\$ 0.25$ for mail order). The differences for total, all third-party payer, and patient costs were statistically significant at $P<0.001$.

\section{Discussion}

The results of this study were based on a large sample of Medicare Part D patients. Within this group, the sample was limited to patients who received no subsidy or premium assistance and who were insured for all of 2010. Further, the sample was limited to prescriptions dispensed for the top 300 products. These accounted for about $85 \%$ of total mail order costs. Consequently, the results of this study should be representative of and generalizable to Medicare Part D patients who do not receive premium or copayment support.

The results of the study indicated that plan sponsors paid more for prescriptions dispensed at mail order pharmacies than for prescriptions dispensed at retail pharmacies. For the comparisons of 90-day and greater supplies, the study showed that total costs, MSB costs, and all third-party payer costs were lower for prescriptions dispensed from retail pharmacies. The comparison for exactly 90-day supplies provided similar results. For the comparison of primarily 90-day mail and primarily 30-day retail prescriptions, all third-party costs were 
lower at retail pharmacies, and MSB costs were about the same for retail and mail order pharmacies. A primary reason for higher plan sponsor costs from mail order pharmacies is that patients paid less of total prescription costs, and plans paid more, when patients used mail order pharmacies.

The results also indicated that the costs of generic drugs were lower and those of branded drugs were higher at retail pharmacies and that retail pharmacies had somewhat higher rates of generic substitution. Khandelwal et al. (2012), in a study comparing 90-day supplies at retail and community pharmacies, also found that retail pharmacies had lower prices for generics and higher prices for branded drugs than mail order pharmacies. ${ }^{18}$ This price difference is somewhat surprising, given that one of mail order pharmacies' cost advantages over retail pharmacies is their ability to earn large discounts from volume purchases of generic products. A report by Martinez (2006) in The Wall Street Journal offers a possible explanation. ${ }^{19}$ This report shows that mail order pharmacies operated by the 3 largest PBMs had very large markups on generic drugs. Martinez also reported that representatives from the PBMs indicated that the large margins on generic drugs were needed to offset low margins on branded products. ${ }^{19}$

Compared with past research, the results of the current study suggest a lower, and for plan sponsors nonexistent, cost advantage for mail order pharmacies. The Lewin Group study (2005) estimated total mail order savings of $10 \%$ across all populations. ${ }^{6}$ Johnsrud et al., using data from 2 state benefit programs in Texas, found that total costs were $12.5 \%$ lower from mail order pharmacies and plan sponsor costs were $0.5 \%$ higher in one plan, and that total costs were $13.7 \%$ lower and plan sponsor costs were $0.4 \%$ lower from mail order for the the other plan that was composed of retirees and their dependents. ${ }^{7}$ Carroll et al. (2005), in a study using data from a small commercial health plan in the Northeast, found total costs were $7.8 \%$ lower, while sponsor costs were $4.8 \%$ higher when mail order pharmacies were used. ${ }^{8}$ One possibility for the differences between the current study and past studies is that the Part $\mathrm{D}$ population is different from the populations examined in earlier studies. The Part D population is older than the samples in most earlier studies (with the possible exception of the retiree plan in Johnsrud's study). ${ }^{7}$ Older patients probably take a different mix of drugs than younger patients. Another possibility is that differences in mail order and retail costs have decreased over time. An analysis based on a survey of plan sponsor reimbursement data suggests that the growth of 90-day retail prescriptions has decreased the total cost difference between mail and retail pharmacies. ${ }^{20}$ This conclusion is supported by the study published by Khandelwal et al., which found no differences in overall allowed charges between 90-day prescriptions dispensed by mail order and retail pharmacies in a large sample of patients insured by employer groups. ${ }^{18}$ Finally, as copayments have increased over time, the cost to plan sponsors of incentivizing patients to use mail order pharmacies by reducing patient copayments has also increased. This inducement would account for higher mail order costs to plan sponsors in our study compared with earlier studies.

This situation presents a dilemma for plan sponsors. They want their members to use mail order pharmacies to realize savings from lower mail order costs. But to induce members to use mail order pharmacies, plans must reduce copayments, which, in turn, reduces or eliminates plan savings. There are at least 2 alternatives for plan sponsors in this situation. First, plan sponsors could try to increase mail order use by requiring their members to use mail order, rather than by incentivizing them with lower copays. While there is little research on this topic, the few available studies and reports indicate that most patients use mail order pharmacies because of reduced copays. ${ }^{10,18,21-23}$ Requiring members to use mail order and not providing lower copayments could result in substantial member dissatisfaction and plan switching. Alternatively, plan sponsors could offer patients a plan design that offers the same copayments for mail order and retail pharmacy. Under this scenario, plans may see fewer prescriptions filled through mail order, but plan sponsors would realize a much larger share of any savings that result from mail order usage.

\section{Limitations}

A limitation of this study was that the comparison of costs was based on the assumption that patients who purchased prescriptions through mail order pharmacies made the same decisions and had the same medication-related behaviors as those who purchased their prescriptions at a retail pharmacy. Because patients face different copayments at mail order and retail pharmacies, they may make different decisions about whether to have prescriptions filled, what quantities to have dispensed, or whether or not to request therapeutic interchanges. Further, patients using mail order pharmacies may be more likely to be enrolled in automatic refill programs. Differences in the convenience of having prescriptions filled, in face-to-face contact with pharmacists, or in quantities dispensed could lead to differences in adherence, persistence, or product waste. Further, patients who use mail order pharmacies have been found to be older $^{24-26}$ and less likely to be minorities ${ }^{24,27}$ than patients who primarily use retail pharmacies. These differences could result in different medication-related behaviors that could, in turn, lead to differences in total costs paid by sponsors.

Our study's results did not account for differences in patient behavior or motivations. Some patients may, for example, prefer mail order because of the convenience of not having to visit a pharmacy. To account for such differences would require a different data source and a different research design than those used in this study. An experimental or quasi-experimental design would be needed to accurately assess differences in patient behavior when switching between mail order and retail pharmacies. 
Another potential limitation of the study was that Medicare Part D data that CMS makes available to researchers do not include rebate information. ${ }^{17,28}$ There are 2 instances in which this absence could affect the results of this study. First, if rebates on mail prescriptions were greater than rebates on retail prescriptions, and if this difference were passed on to plan sponsors, then some of the higher mail order costs documented in this study would be offset. While little is known about rebates because of the confidential nature of rebate contracts, manufacturers would seem unlikely to pay a higher rebate because a drug was sold through one channel rather than another. More likely, the manufacturer would be primarily concerned with how much of the drug was sold, not the channel through which it was sold. Second, if mail order pharmacies were more effective at switching patients to preferred products than retail pharmacies, then they would earn greater rebates. To the extent these savings were passed on to plan sponsors, higher mail order costs would be offset. A search of the literature revealed no studies examining this issue.

The study sample of 300 products (GPIs) was selected based on dollar volume rather than prescription volume. This selection criterion was based on the assumption that plan sponsors and Medicare would be more interested in dollars spent than in numbers of prescriptions dispensed. The results may have been slightly different if the sample had been based on numbers of prescriptions. That sample would have probably included more generic and less brand-name products. Given that we found that retail pharmacies were more likely to have lower costs for generic products, a sample based on numbers of prescriptions would have shown lower costs and greater cost savings for retail pharmacies.

One result of defining products by GPI was that cost differences reflected both differences in pricing and differences in generic substitution rates between retail and mail order pharmacies. If the study had defined branded drugs and their generic equivalents as separate products, the results may have been somewhat different. This analysis would have probably included more generic, and less branded, drugs. Such a result would have occurred because many products (as defined by GPIs) consisted primarily of generic drugs but also included some branded drugs. The top 300 drugs, in an analysis that treated branded and generic drugs as different products, would likely have included the generic versions of these products but not the branded versions. To the extent that retail pharmacies provide lower prices on generic products, this analysis would have shown greater cost savings from retail pharmacies. Results for branded drugs were unlikely to have been different than those in the current study because any branded products included in a GPI that included generics would probably not have had sufficient sales volume to be included in the top 300 products, if they were considered as separate products.

\section{Conclusions}

This study compared the costs of prescriptions dispensed by mail order and retail pharmacies. Results based on a large sample of Medicare Part D patients indicated that when comparing 90-day or greater supplies of medication, retail pharmacies provided lower total costs, MSB costs, and all third-party payer costs. Even when comparing 30-day retail and 90-day mail prescriptions, plan sponsors did not realize savings by using mail order pharmacies. These results did not incorporate differences in patient behavior that may have affected adherence and persistence, waste, therapeutic interchange, or rebates between mail order and retail pharmacies. Such differences could affect the cost savings, or losses, that plan sponsors realized by using mail order pharmacies.

\section{Author}

NORMAN V. CARROLL, PhD, is Professor of Pharmacoeconomics and Health Outcomes, School of Pharmacy, Virginia Commonwealth University, Richmond, Virginia.

AUTHOR CORRESPONDENCE: Norman V. Carroll, PhD, Professor of Pharmacoeconomics and Health Outcomes, School of Pharmacy, Virginia Commonwealth University, 410 N. 12th St., POB 980533, Richmond, VA 23298-0533. Tel.: 804.828.2587; Fax: 804.628.3991; E-mail: nvcarroll@vcu.edu.

\section{DISCLOSURES}

This research was supported by a grant from the NCPA Foundation. The author reports no other financial or potential conflicts of interest related to the subject of this article. The sponsor had no role in the design and conduct of the study; collection, management, analysis, and interpretation of the data; or preparation or approval of the manuscript. The sponsor reviewed and provided comments on the manuscript prior to submission for publication but had no authority over the content of this manuscript.

\section{REFERENCES}

1. Pharmacy Benefit Management Institute. The Takeda prescription drug benefit cost and plan design survey report: 2006 edition. Scottsdale, AZ: Pharmacy Benefit Management Institute; 2006.

2. Pharmacy Benefit Management Institute. The prescription drug benefit cost and plan design report: 2011-2012. Available at: www.pbmi.com/shop/ prescription-drug-benefit-cost-and-plan-design-reports/2011-2012-prescription-drug-benefit-cost-plan-design-report/. Accessed July 7, 2014.

3. Horgan C, Goody B, Knapp D, Fitterman L. The role of mail service pharmacies. Health Aff (Millwood). 1990;9(3):66-74.

4. Kirking DM, Ascione FJ, Richards JW. Choices in prescription-drug benefit programs: mail versus community pharmacy services. Milbank $Q$ 1990;68(1);29-51

5. Enright SM. Mail order pharmaceuticals. Am J Hosp Pharm. 1987;44(8):1870-73. 6. Lewin Group. Mail-service pharmacy savings: a ten-year outlook for public and private purchasers. August 2005. Available at: http://www.lewin. com/publications/publication/233\%. Accessed June 13, 2014. 
7. Johnsrud M, Lawson KA, Shepherd MD. Comparison of mail order with community pharmacy in plan sponsor cost and member cost in two large pharmacy benefit plans. J Manag Care Pharm. 2007;13(2):122-34. Available at: http://www.amcp.org/WorkArea/DownloadAsset.aspx?id=7541.

8. Carroll NV, Brusilovsky I, York B, Oscar R. Comparison of costs of community and mail service pharmacy. J Am Pharm Assoc (2003). 2005:45(3):336-43.

9. Visaria J, Seoane-Vazquez E, Szeinbach SL, Rodriguez-Monguio R. Comparing the cost of community pharmacy and mail order pharmacy in a US retirement system. Int J Health Plann Manage. 2012;27(1):e41-e50.

10. Clark BE, Siracuse MV, Garis RI. A comparison of mail-service and retail community pharmacy claims in 5 prescription benefit plans. Res Social Adm Pharm. 2009;5(2):133-42.

11. Wosinska M, Huckman RS. Generic dispensing and substitution in mail and retail pharmacies. Health Aff (Millwood). 2004;Suppl Web Exclusives: W4-409-16.

12. Lewin Group. Mail-service pharmacy savings and the cost of proposed limitations in Medicare and the commercial sector. September 2006. Available at: http://www.lewin.com/ /media/Lewin/Site_Sections/ Publications/3480.pdf. Accessed June 13, 2014.

13. U.S. Federal Trade Commission. Pharmacy benefit managers: ownership of mail order pharmacies. August 2005. Available at: http:// www.ftc.gov/sites/default/files/documents/reports/pharmacy-benefitmanagers-ownership-mail-order-pharmacies-federal-trade-commissionreport/050906pharmbenefitrpt_0.pdf. Accessed July 3, 2014

14. Access to Covered Part D Drugs. 42 CFR \& 423.120.

15. Fein AJ. The great mail pharmacy slowdown. Drug Channels. April 13, 2012. Available at: www.drugchannels.net/2012/04/great-mail-pharmacyslowdown.html. Accessed June 13, 2014

16. Liberman JN, Girdish C. Recent trends in the dispensing of 90-daysupply prescriptions at retail pharmacies: implications for improved convenience and access. Am Health Drug Benefits. 2011;4(2):95-99. Available at: http://s3.amazonaws.com/zanran_storage/www.ahdbonline.com/ ContentPages/2466156042.pdf. Accessed July 7, 2014.

17. Centers for Medicare and Medicaid Services. Questions and answers on obtaining prescription drug event (PDE) data. Available at: http://www.cms. gov/Medicare/Prescription-Drug-Coverage/PrescriptionDrugCovGenIn/ downloads/PartDClaimsDataQA.pdf. Accessed June 13, 2014.
18. Khandelwal N, Duncan I, Rubinstein E, Ahmed T, Pegus C. Community pharmacy and mail order cost and utilization for 90-day maintenance medication prescriptions. J Manag Care Pharm. 2012;18(3):247-55. Available at: http://www.amcp.org/WorkArea/DownloadAsset.aspx?id=14972.

19. Martinez B. Selling generic drugs by mail turns into lucrative business. The Wall Street Journal. May 9, 2006:A1.

20. Fein AJ. Retail and mail pharmacy economics start converging. Drug Channels. October 27, 2011. Available at: http://www.drugchannels. net/2011/10/retail-and-mail-pharmacy-economics.html. Accessed June 13, 2014

21. Birtcher KK, Shepherd MD. Users' perceptions of mail-service pharmacy. Am Pharm. 1992;NS32(12):35-41.

22. Fried, LI. Rite Aid levels "paying" field between drug-store and mail order prescriptions. Drug Store News. 1998;20(8):CP4

23. Patients prefer independents to mail order. Drug Topics. 1999;143(5):10.

24. Duru OK, Schmittdiel JA, Dyer WT, et al. Mail order pharmacy use and adherence to diabetes-related medications. Am J Manag Care. 2010;16(1):33-40

25. Liberman JN, Wang Y, Hutchins DS, Slezak J, Shrank WH. Revealed preference for community and mail service pharmacy. J Am Pharm Assoc (2003). 2011;51(1):50-57.

26. Zhang L, Zakharyan A, Stockl KM, Harada AS, Curtis BS, Solow BK. Mail order pharmacy use and medication adherence among Medicare Part D beneficiaries with diabetes. J Med Econ. 2011;14(5):562-67.

27. Johnson JA, Coons SJ, Hays RD, Sabers D, Jones P, Langley PC. A comparison of satisfaction with mail versus traditional pharmacy services. J Manag Care Pharm. 1997;3(3):327-37. Available at: http://www.amcp.org/ WorkArea/DownloadAsset.aspx?id=5855.

28. Centers for Medicare and Medicaid Services. CMS guide to requests for Medicare Part D prescription drug event (PDE) data. March 2008. Available at: http://www.cms.gov/Medicare/Prescription-Drug-Coverage/ PrescriptionDrugCovGenIn/Downloads/GuidePartDv3-3-17-09-2.pdf. Accessed June 13, 2014

29. Centers for Medicare and Medicaid Services. Instructions: requirements for submitting prescription drug event data. April 26, 2006. Available at: http:// www.cms.gov/Medicare/Prescription-Drug-Coverage/DrugCoverageClaimsData/ downloads/PDEGuidance.pdf. Accessed June 13, 2014

30. Research Data Assistance Center. Part D drug event file. Available at: http://www.resdac.org/cms-data/files/pde/data-documentation. Accessed June 14, 2014 